\title{
INVESTIGATION TO IMPROVE THE SAND MOLDING FORMULA OF THE ERG BY INCORPORATING LOCAL MATERIALS
}

\author{
M. DAHMANI, A. TAFRAOUI, S. TAFRAOUI, \\ A. CHAOUFI \& M. ZAOUI \\ Department of Mechanical Engineering, University of TAHRI Mohamed BECHAR,
}

Mechanical Engineering Reliability Laboratory, Bechar, Algeria

\begin{abstract}
In the field of molding, the use of a large quantity of sand from the beach causes an ecological problem for Algeria, plus its price which keeps increasing in the Algerian market leads to the search for solutions, to replace this type of sand which was nowadays among the first concerns of the country. Thus the proposal to substitute beach sand by the sand of Western ERG of Algeria gave satisfactory results presented on a first place as a simple and effective solution, knowing that this type of sand is in abundance and occupies nearly $6 \%$ of the surface of our country. The subject on which this work focuses is part of the problematic associated with the study of valorization of the sand of the ERG in the process of molding of parts and the investigation to the improvement of the sand casting formula of the ERG by incorporating local materials. However, the development of ERG sand has an economic and ecological impact for Algeria. Among other things, the addition of Bentonite in the molding formulation is an economic problem because this type of material is very rare, very expensive and is currently imported from abroad. Indeed, we want to improve the sand molding formula of the ERG by adding materials that replace the Bentonite to greatly reduce manufacturing costs in molding. The investigation in this area is relevant to our country.
\end{abstract}

KEYWORDS: Molding, ERG Sand, Formulation, Surface Condition, Ecology \& Binder

Received: May 27, 2018; Accepted: Jun 17, 2018; Published: Jul 16, 2018; Paper Id.: IJMPERDAUG201853

\section{INTRODUCTION}

Basically, sand casting is a process where the mold is fabricated by patterning a refractory material to form a cavity of the desired shape so that the molten metal can be cast into the cavity. The mold cavity should retain its shape until the metal is solidified and the molded product is removed. This may seem simple, but depending on the choice of metal, the mold must have certain characteristics. In case of projection clamping molding, shaking or pressure molding can be used to form the mold, wooden or plastic patterns. High density and high-pressure sand casting and casting methods almost always require metal model equipment. High density and high-pressure casting normally produce a well pressed mold which produces better surface qualities, dimensions, and tolerances of the cast product. Green casting properties are adjustable over a broad spectrum, allowing this process to be used with all types of green casting equipment for a majority of cast alloys.

The most commonly used method in sand casting manufacturing is casting to green. In this process, the granular refractory sand is coated with a mixture of Bentonite clay, water and, in some cases, other additives. The additives help to harden and hold the shape of the mold to withstand the pressures of the molten metal. 
The green sand mix is mechanically compressed or hand-compressed around a pattern to create a mold. The mechanical force required for the sand molding process can be induced by projection, shaking or compression molding $[1,5,4,8,11,13]$. For many metal applications, green casting processes are the most cost-effective of all metal forming operations. These processes lend themselves easily to automated systems for large volumes of work as well as for small series and prototype work. It is aimed at molding either for the manufacture of complicated shapes that would be difficult or impossible to achieve by any other method, either for production at more interesting cost prices of simpler parts, or to take advantage of physical properties or use (expansion, corrosion, friction, wear, low and high temperatures) and mechanical properties of various metals and cast alloys, or finally to cast non-corrodible alloys or difficult machining.

The molding operation is one of the most important of the foundry's industrial process. It determines, according to the model, the shapes of the part to be cast, its dimensions and their precision, its surface conditions; it's cooling and plays a preponderant role on many parameters influencing its quality. Many molding processes exist and this very wide variety of processes requires classifying them to allow their presentation. [2, 3, 6, 7, 10, 12]

We generally classify them according to the molding and hardening modes of the materials used at the time of manufacture of the mold or cores and the nature of the models that must be compatible with the processes used. After an exhaustive presentation of the molding processes, we will study more precisely the molding technique using dune sand from the western ERG of the south-west region of ALGERIA. The molding process has become very expensive today in terms of prices and transport costs and illustrates the example of an economic study conducted in France in 2005 as shown in the following table (Table 1), while in our southernmost most materials and molding raw material are available and for many years.

The quantity of new siliceous sand sold to French foundries is about 600000 tonnes in 2005 (source SIFRACO and FULCHIRON) which are the two main suppliers.

Table 1: Cost of New Sand for 1 ton of Sand without Preparation

\begin{tabular}{|l|c|c|c|c|c|c|}
\hline \multirow{2}{*}{} & $\begin{array}{c}\text { Buying } \\
\text { Price }\end{array}$ & $\begin{array}{c}\text { Cost Excluding } \\
\text { Transport }\end{array}$ & $\begin{array}{c}\text { Transport } \\
\text { Price }\end{array}$ & Distance & $\begin{array}{c}\text { Transport } \\
\text { Cost }\end{array}$ & \multirow{2}{*}{ Total } \\
\cline { 2 - 6 } & DA/t & For $\mathbf{1 ~ t}$ & DA/t/km & $\mathbf{k m}$ & For 1 t & \\
\hline Sand (88\%) & 1530 & 1350 & 63 & 200 & 1108,8 & \\
\hline Bentonite (8\%) & 13500 & 1080 & 81 & 350 & 226,8 & \\
\hline Carbon additive (4\%) & 23400 & 936 & 162 & 200 & 129,6 & \\
\hline Total new sand & & 3366 & & & 1465,2 & 4831,2 \\
\hline
\end{tabular}

\section{MATERIALS AND METHODS}

\section{Materials}

The materials used for the formulation of molding sand are: (Figure 1)

- Western ERG dune sand from the Bechar area (see Tables 2 and 3)

- $\quad$ Bentonite (local clay) (see Table 4 and 5): The clay (Bentonite) that binds the silica grains together and prevents the mold from deteriorating after removal of the model. In some cases instead of clay, other binders such as vegetable oils, water glass, resins, bitumen's, sulfuric lye etc. are used. Bentonite is imported clay available in the white colloid powder market named after Fort Benton, Wyoming, USA. Also known as fuller's earth, it can be considered as a smectite, consisting essentially of montmorillonite and clay, which explains its water retention 
capacity. Other minerals such as quartz, mica, feldspar, pyrite or calcite are also found. The deposits of Bentonite are of volcanic and hydrothermal origins.

Bentonite has various properties. In particular, it absorbs proteins, reduces the activity of enzymes. Bentonite sludge (containing a fraction of Bentonite) is used in earthworks, molded walls, because of their ability to leave the room quickly and easily poured concrete in their place. The CAS number of the Bentonite is 1302-78-9. Source tap water (local water supply)

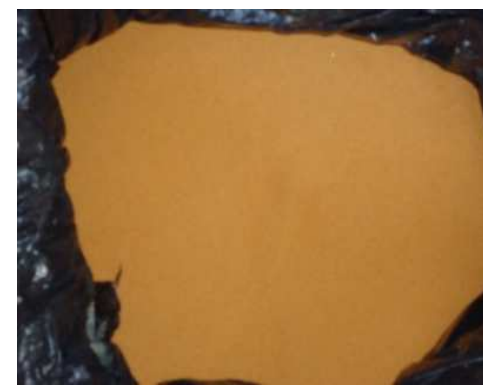

Sand Dune

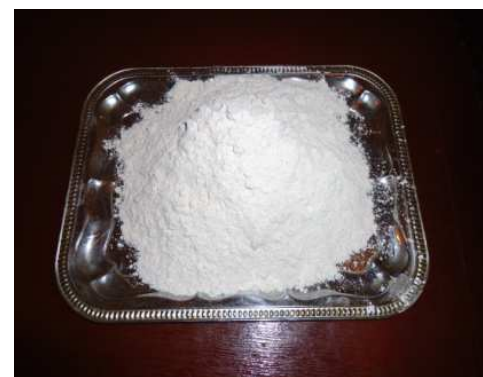

Bentonite

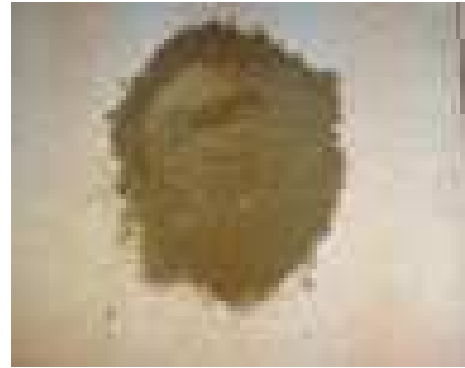

Local Clay

Figure 1: Materials Used

Table 2: Chemical Characteristics of Dune Sand in \%

\begin{tabular}{|c|c|c|c|c|c|c|c|c|c|}
\hline Oxides & $\mathbf{S i O}_{2}$ & $\mathbf{A L}_{2} \mathbf{O}_{3}$ & $\mathbf{F e}_{2} \mathbf{O}_{3}$ & $\mathbf{M g O}$ & $\mathbf{C a O}$ & $\mathbf{N a}_{2} \mathbf{O}$ & $\mathbf{K}_{2} \mathbf{O}$ & $\mathbf{S O}_{3}$ & Fire Loss \\
\hline$(\%)$ & 97.33 & 0.830 & 0.24 & 0.41 & 0.07 & 0.09 & 0.04 & 0.18 & 0.40 \\
\hline
\end{tabular}

Table 3: Physical Characteristics of the Sand Dune

\begin{tabular}{|c|c|c|c|}
\hline $\begin{array}{c}\text { Specific Surface BET } \\
\left(\mathbf{c m}^{2} / \mathbf{g}\right)\end{array}$ & $\begin{array}{c}\text { Average Size, D50 } \\
(\boldsymbol{\mu m})\end{array}$ & Actual Density & Hardness \\
\hline 115 & 200 & 3 & 7 \\
\hline
\end{tabular}

Table 4: Chemical Characteristics of Bentonite in \%

\begin{tabular}{|c|c|c|c|c|c|c|c|c|c|c|c|}
\hline oxides & $\mathbf{S i O}_{2}$ & $\mathbf{A L}_{2} \mathbf{O}_{3}$ & $\mathbf{F e}_{2} \mathbf{O}_{3}$ & $\mathbf{M g O}$ & $\mathbf{C a O}$ & $\mathbf{N a}_{2} \mathbf{O}$ & $\mathbf{K}_{2} \mathbf{O}$ & $\mathbf{M n O}$ & $\mathbf{T i O}_{2}$ & $\mathbf{H}_{2} \mathbf{O}$ & $\mathbf{S i O}_{2} / \mathbf{A L}_{2} \mathbf{O}_{3}$ \\
\hline$(\%)$ & 61,01 & 16,10 & 2,80 & 3,53 & 3,15 & 1,50 & 1,60 & 0,04 & 0,22 & 10,16 & 6,44 \\
\hline
\end{tabular}

Table 5: Characteristics of Bentonite (Trace Elements)

\begin{tabular}{|c|c|c|c|c|c|c|c|}
\hline Trace Elements & $\mathbf{B a}$ & $\mathbf{S r}$ & $\mathbf{C u}$ & $\mathbf{P b}$ & $\mathbf{Z n}$ & $\mathbf{S}$ & $\mathbf{S O}_{\mathbf{4}}$ \\
\hline PPM & 210 & 160 & 20 & 35 & 70 & 270 & 810 \\
\hline
\end{tabular}

Methods

Physicochemical study of the Sand of Western ERG (South-West of Algeria)

The sands studied are from:

- $\quad$ The region of Taghit (BECHAR Wilaya).

- $\quad$ The region of Igli (BECHAR Wilaya).

- The region of Beni Abbes (BECHAR Wilaya).

The microscopic observations made on one of these sands (Taghit sand) (Figure I-1 and I-2) showed that the samples consist essentially of quartz $\left(\mathrm{SiO}_{2}\right)$ in the form of rounded and sub-rounded grains. The presence of iron oxides $\left(\mathrm{Fe}_{2} \mathrm{O}_{3}\right)$ has also been detected either in the form of independent grains or in the form of inclusions or coating of the quartz 


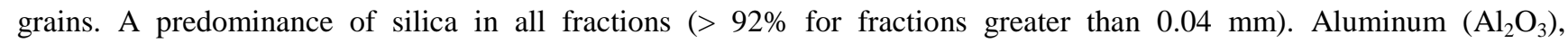
calcium $(\mathrm{CaO})$ or iron $\left(\mathrm{Fe}_{2} \mathrm{O}_{3}\right)$, and potassium $\left(\mathrm{K}_{2} \mathrm{O}\right)$ are in decreasing percentage, while other elements such as Ti, $\mathrm{P}, \mathrm{Mn}$, $\mathrm{Cr}, \mathrm{Na}$ are in the form of traces $(<1 \%)$.

Several methods have been used to characterize Western ERG sand such as:

- $\quad$ Particle size analysis (Figure 3)

- $\quad$ Microscopic observation (Figure 2)

- $\quad$ Elemental analysis by X-ray diffractometry (Figure 4)

Thus, it can be concluded that the sand of the western ERG of south-west Algeria constitutes a deposit rich in fine particles. Fractions of 0.10 to $0.25 \mathrm{~mm}$ seem the most interesting because the richest in silica. [9]

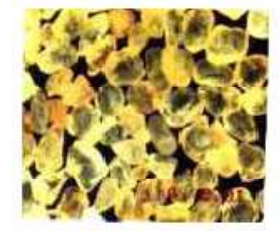

corroded grain

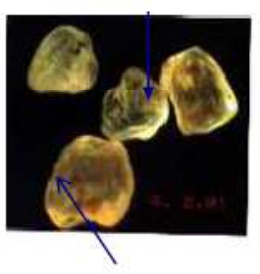

rounded grain
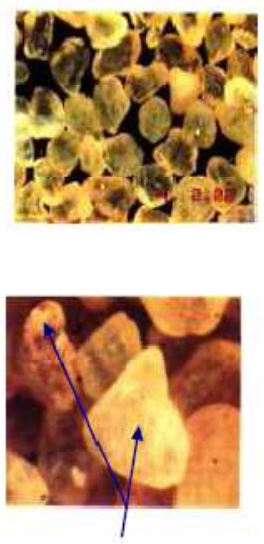

broken grains
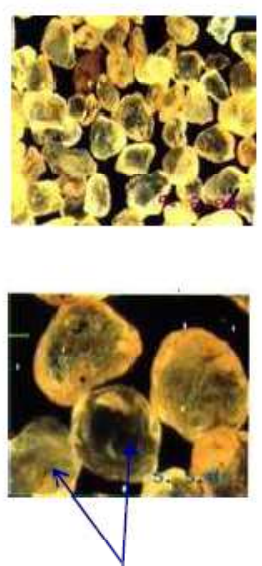

dappled grains

Figure 2: Observations of Sand Grains under an Optical Microscope [9]
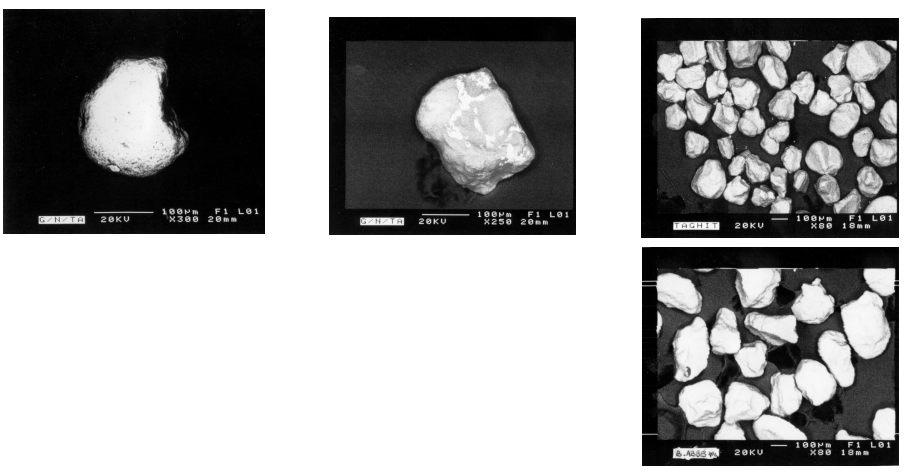

Figure 3: Observations of Sand Grains at MEB [9] 


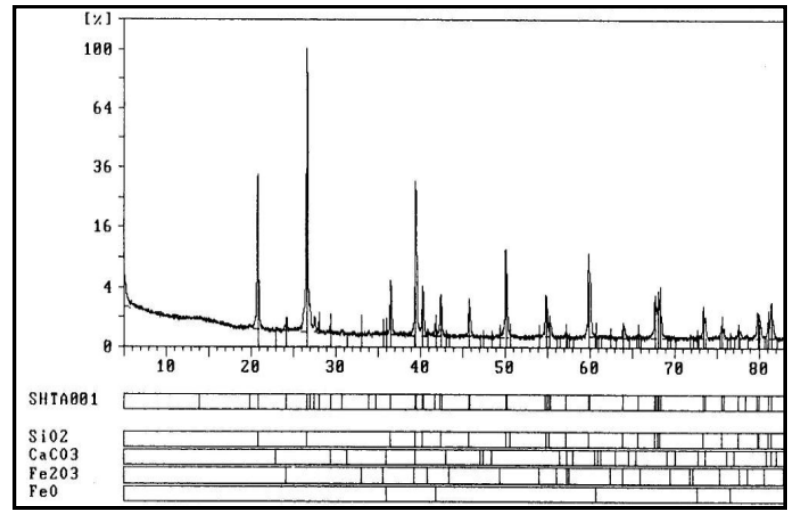

Figure 4: XRD Analysis of TAGHIT Sand [9]

\section{Realization of the Mold}

Tools for Making Molds and Models (Figure 5)

Materials for mold design

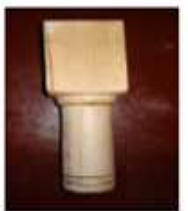

Rammer

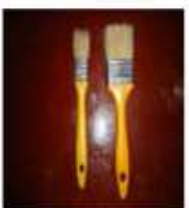

Paint brushes

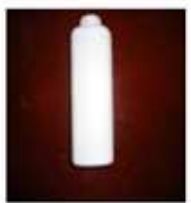

Talcum powder

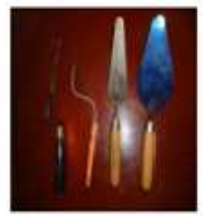

Trowels Casting channel and needle

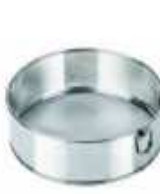

Sieve

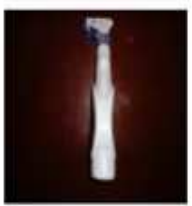

Water sprayer

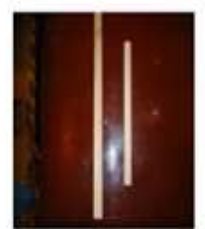

Compacting rules
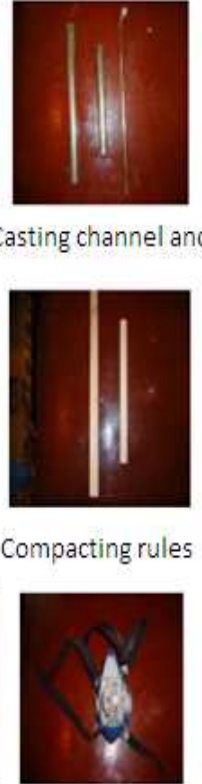

Anti dust mask

Figure 5: Molding Equipment and Tools

\section{Mold Making (Figure 6)}

We made the red wooden molds of thickness $20 \mathrm{~mm}$ and in three different forms: 30x30cm, 24x18cm, 20x14cm, so they are equipped with locating pins and guiding and lifting wrists on their sides. These marking pins are made of metal material with fixing screws. Moreover, we proceeded to strengthen these molds at their corners by metal flats. To avoid any cracking of the wood we have introduced these molds in a tray of wool oil in two separate times to ensure better absorption. 


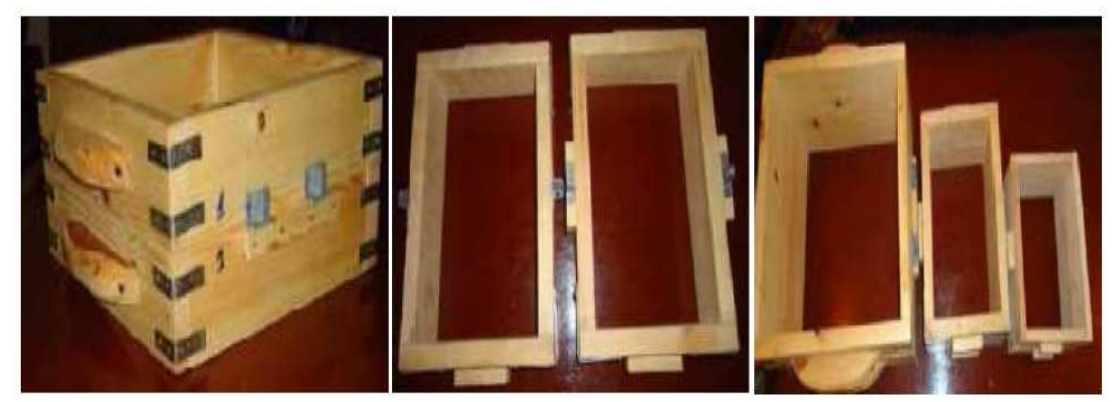

Figure 6: Different Types of Molds for Molding

\section{Choice of Models (Figure 7)}

The making of the models is made of wood, plastic, wax or Bakelite however, this operation is very delicate requiring a modeller to qualify, for this purpose we proceeded to the making of the models using the used parts of lightweight so that the machined part of these is camouflaged by a sticky paste that hardens quickly (Figure 4).
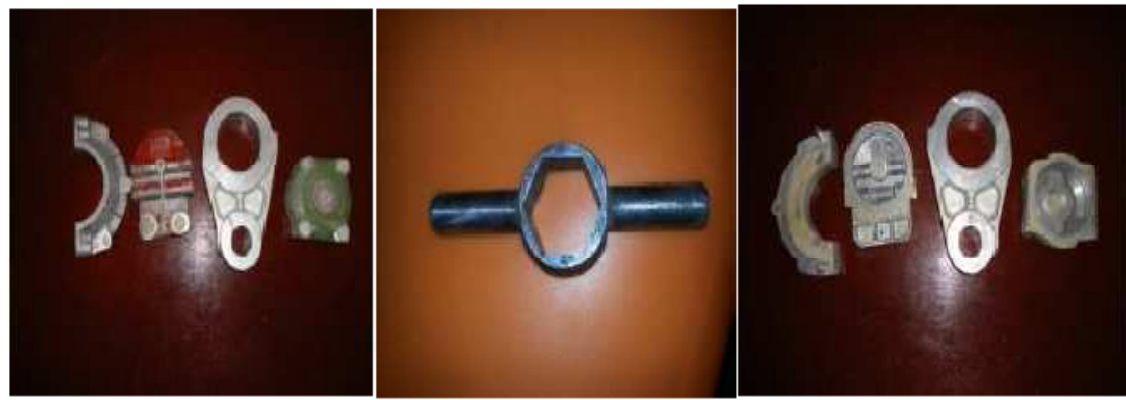

Figure 7: Models

\section{Formulation (Figure 8)}

The formulation used is presented in Table 6:

Table 6: Formulation of Molding Sand

\begin{tabular}{|l|c|}
\hline \multicolumn{1}{|c|}{ Materials } & Amount (\%) \\
\hline Sand dune of the ERG & 70 à 80 \\
\hline Bentonite (local white clay) & 15 à 20 \\
\hline Water & 8 à 10 \\
\hline
\end{tabular}

The sand/water mixture and additional Bentonite (local clay) is done in the mixer or manually, slowly so as not to create clumps and until total humidification of the sand and to ensure a certain permeability for degassing. We then recover the sand in a tray. This sand is then ready to be used to make the molding. We seek to obtain a clay mixture. It is therefore, necessary to have the appropriate amount of water to avoid having mud in case of excess water and crumbling in the opposite case. It takes 8 to $10 \%$ of specific water for $70 \%$ of sand and $20 \%$ of Bentonite (local clay). However, the problem lies in the fact that the sand already contains a certain amount of water due to the humidity of the air. It would be necessary to determine how much it contains to know how much to add. For this purpose, a certain amount of sand is weighed before and after baking, assuming that the difference in mass is due to the evaporation of the water contained in the sand in the oven. We did not carry out this calculation of the quantity of water during our experiment, because the climate of the region is very dry so the quantity of water in mass is very negligible and does not exceed the $0.2 \%$ of water in mass. 
Therefore we had to add to $10 \mathrm{~kg}$ of sand a volume of $800 \mathrm{ml}$ of water.

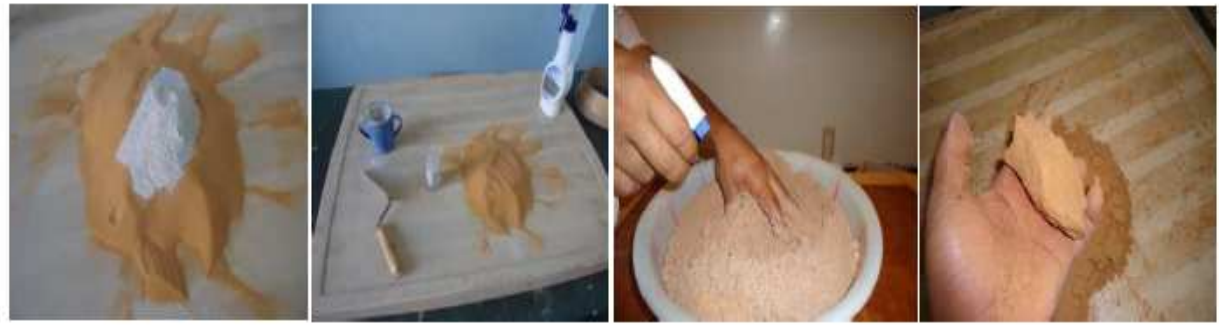

Figure 8: Formulation of Molding Sand

\section{Molding}

\section{Operating Mode}

We want to achieve a very good footprint and a satisfactory traceability of the model. The model is placed on a smooth and clean surface (Figure 9a) on which is the lower frame (Figure 9b) and then we model a small amount of TALC powder on the model to facilitate demolding, (Figure 9c). The filling of the frame will be carried out progressively (Figure 9 d) by sand while compacting it with the aid of the hammer and the palette (Figure 9 e).

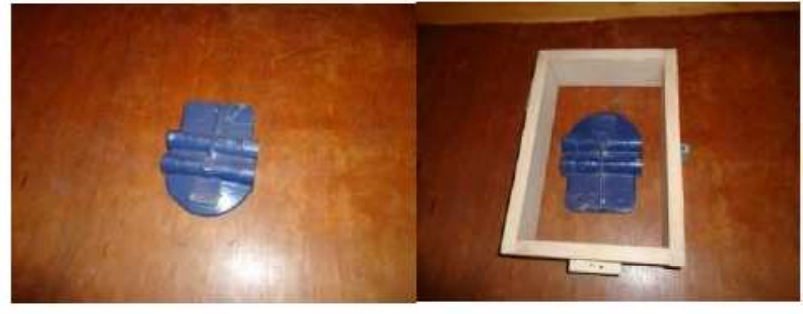

(a)

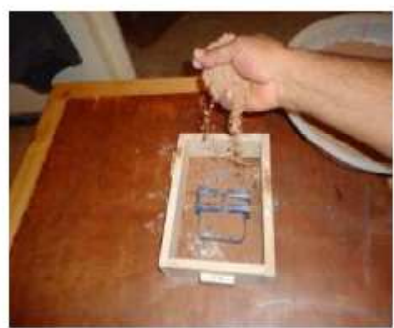

(d) (b)

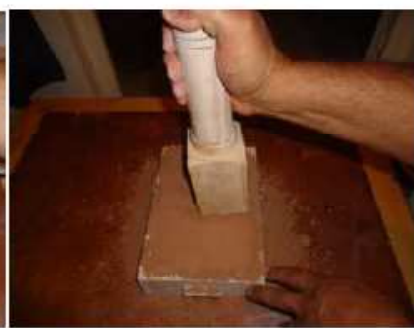

(e)

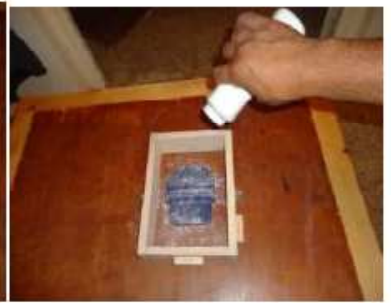

(c)

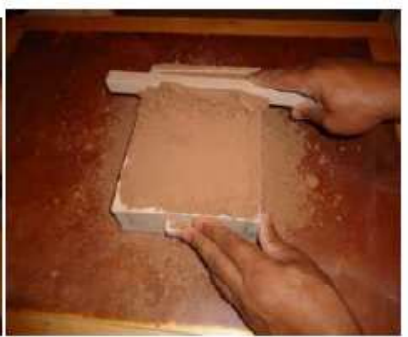

(f)

Figure 9: Manufacture of the Lower Part of the Mold (Carcass of an Aluminum Fuel Filter)

\section{Making the Upper Part of the Mold (Figure 10)}

For the upper part of the mold: we position the second part of the model on the first one, then we put the model (Figure $10 \mathrm{a}$ ).

The positioning is performed by centering studs. In any case, this positioning must not be neglected, which is decisive in the positioning of each half-mold relative to the plane of the joint. Then, the casting mandrel and the vent mandrel are pushed slightly into the sand while leaving a cavity for the flyweight (Figure. 10b, c). 


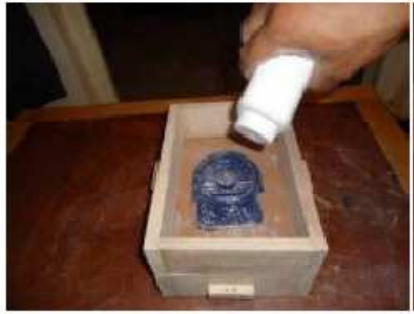

(a)

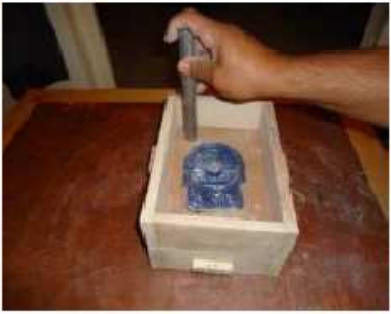

(b)

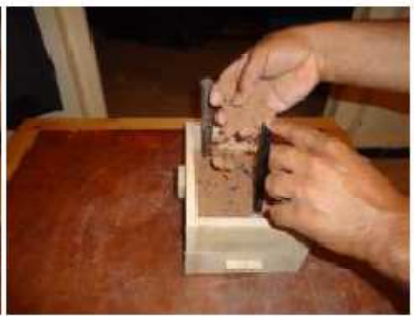

(c)

Figure 10: Making the Upper Part of the Mold

The first amount of sand deposited on the model must be sieved to ensure that no clods are inserted and especially that the sand will perfectly fit the shape of the model. We fill up to a height of a few centimeters before starting to pack. We fill the mold with sand up to the level of the frame. We scrape the extra thickness with a metal or wooden ruler. We obtain a flat surface at the height of the frame. It remains to remove the model from the mold.

\section{Demolding}

- $\quad$ Before separating the two frames, remove the casting and vent mandrel.

- Slowly removing the model after shaking it (Figure $11 \mathrm{a}, \mathrm{b}$ ).

- $\quad$ See different impressions after demolding (Figure 12)

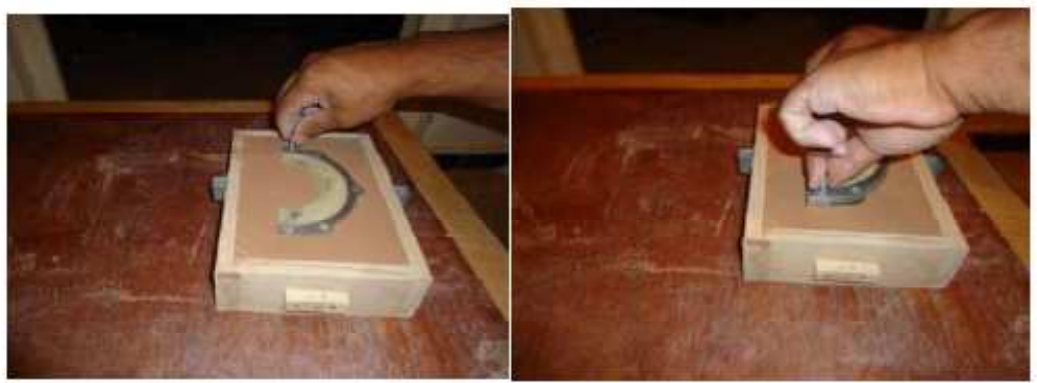

(a)

Figure 11: Demolding

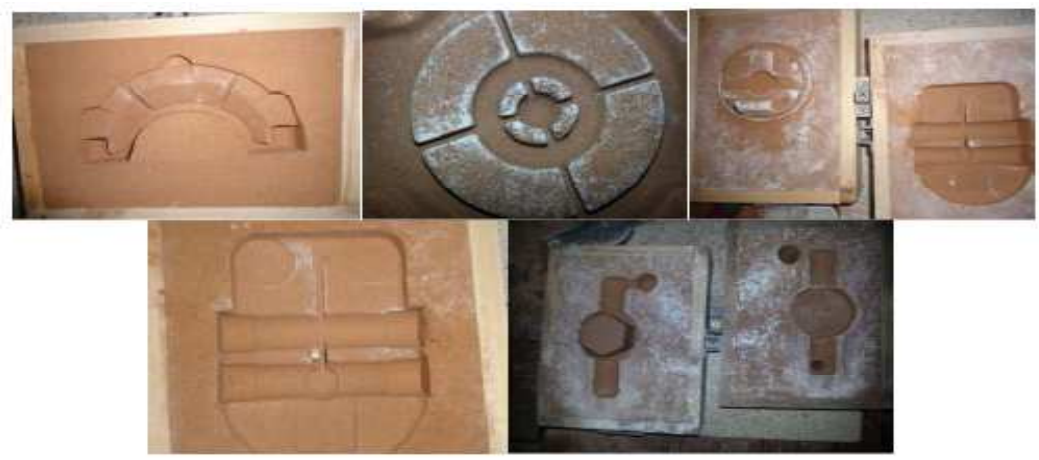

Figure 12: Different Impressions after Demolding 


\section{Remolding (Figure 13)}

- The upper frame is placed on the lower frame while checking their position and contact. (Figure 13 a)

- In order to avoid the lifting of the upper frame, screw fasteners are made or we put on the latter weights to ensure a certain pressure during the casting of the metal and then laying the casting channel and the vent channel (Figure13 c).

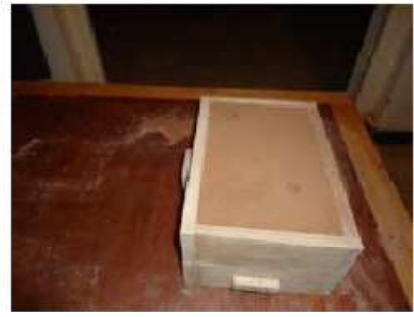

(a)

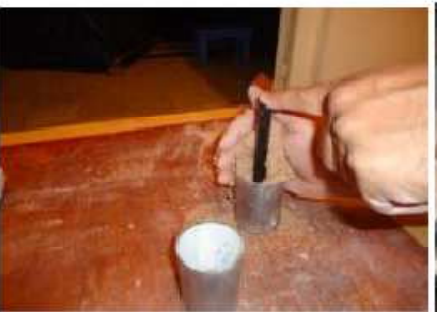

(b)

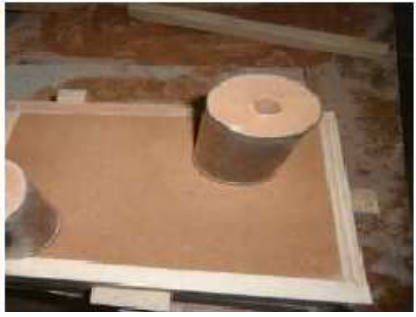

(c)

Figure 13: Remolding

- $\quad$ See the case of a cored molding (Figure 14)

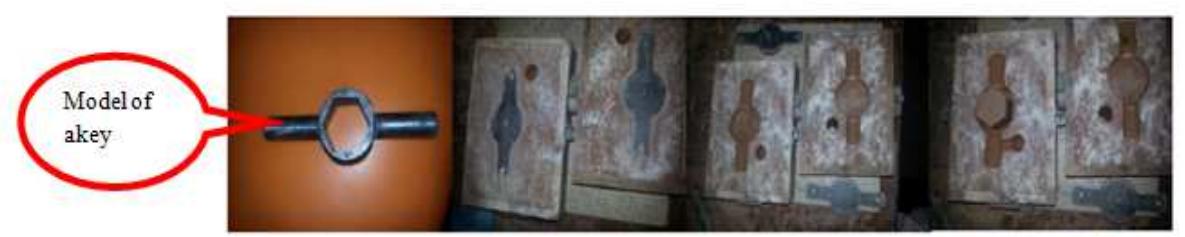

Figure 14: Core Casting

\section{Pouring of the Liquid Metal}

At first, the lead was used as casting metal for the production of the blank.

For the second test, pure aluminum was used as casting metal.

- The liquid metal, intended to fill the impression of the mold, is obtained after melting the lead or aluminum in a crucible (Figure 15), representing a preheated refractory ceramic container or a metal bowl made of heat-resistant steel at the temperature of fusion of aluminum.

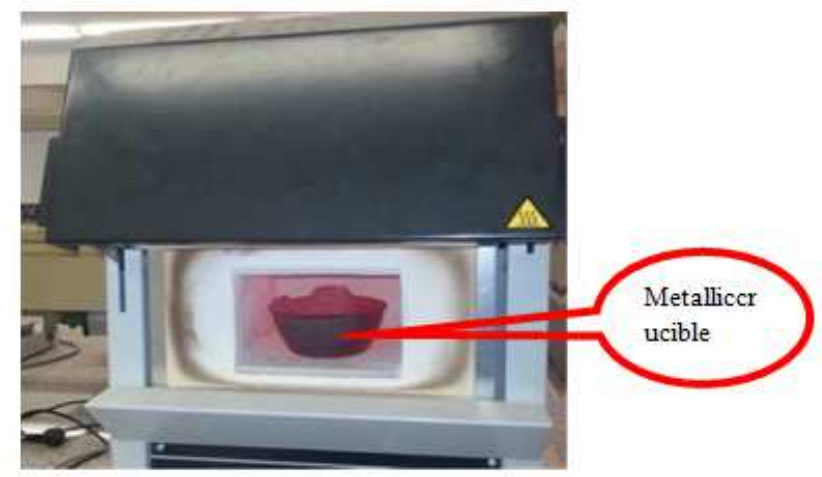

Figure 15: Fusion of Lead and Aluminum 
- The liquid metal is poured through the taphole until it is completely filled (Figure 16). When the quantity of metal to be poured is relatively large or when the part represents high parts, we add weights, wholevolume.

- In order to avoid metal leaks that occur in the mold joint plane due to the vertical thrust of the metal entering the cavity, the frame is loaded with weights (or the two frames are connected by studs).

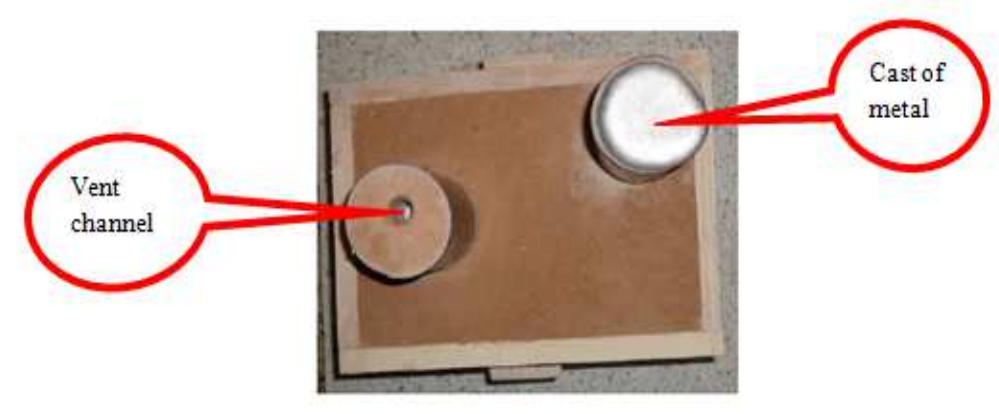

Figure 16: Casting System

Stall

- The shakeout of the work piece will start only when the temperature is low enough when the work piece is fully solidified (Figure 17)

- The casting system and the counterweight are separated from the work piece with a hacksaw without any damage to the work piece.

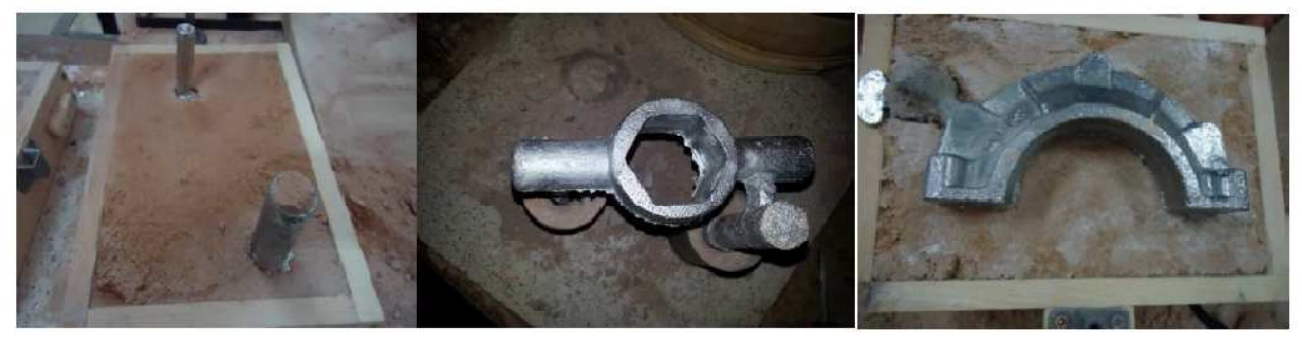

Figure 17: Raw Parts after Shakeout

\section{Sand Blasting}

In contact with cold sand, the metal cools rapidly and its outer surface is coated with grains of sand for this purpose and in order to rid the piece of sand that adheres to its surfaces, it is necessary to go to the grit removal operation. it is most often carried out by sand descaling (very dry silica sand shock) or shot-blasting by means of a jet of compressed air (Figure. $18 \mathrm{a}, \mathrm{b})$. 


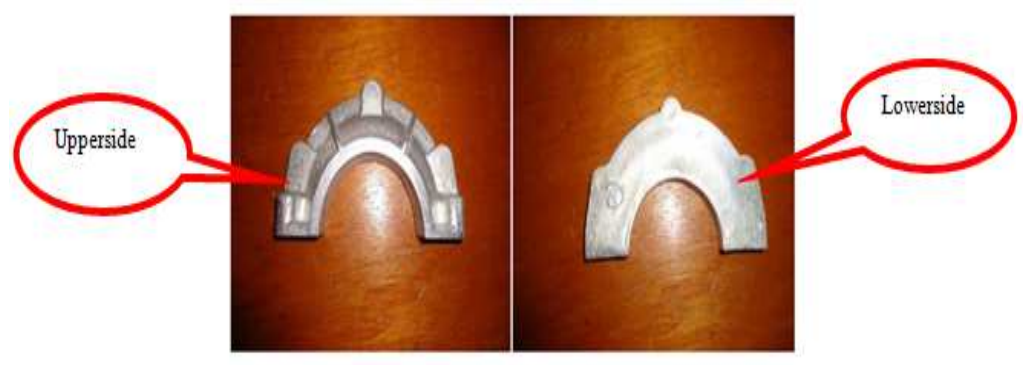

(a)

(b)

Figure 18: Parts after Grit Removal

\section{DeBurring}

Deburring consists in eliminating the casting heel, the burrs at the joints, the spikes of the tapholes and the roughnesses, it is usually performed by grinding (Figure 19 a, b) .

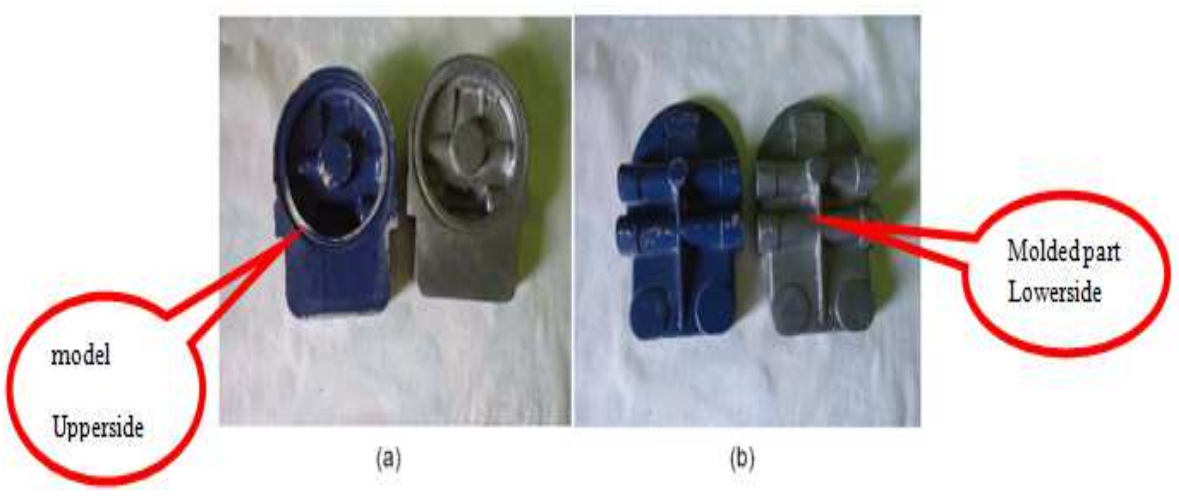

Figure 19: Parts after DeBurring

Control and Heat Treatment: If applicable

Machining, Finishing, and Drilling: If applicable.

\section{RESULT AND DISCUSSIONS}

After several tests, we came to conclude that a quantity of $20 \%$ of Bentonite (local clay), $10 \%$ of natural water and $70 \%$ of sand, gave us a much-needed humidification, plasticity and cohesion so this formulation has met several very important characteristics for the realization of our experience which is the "Sand dune molding" such as:

- The faithful reproduction of the model piece.

- $\quad$ The surface condition as fine as possible.

- The sand does not disintegrate during the extraction of the model.

- Resistance to the high temperature of the metal during casting.

- $\quad$ Resistance to erosion by the liquid metal during casting.

- $\quad$ The permeability to allow the passage of gases produced during casting. 
- $\quad$ The easy stall.

However, we did not introduce organic binders or adjuvants that are commonly used to promote demolding and shakeout to fully understand the behavior of our sand in conventional molding. Dune sand has given us good results in the molding process without recycling or organic additions at very high temperatures with a good appearance of the model.

\section{CONCLUSIONS}

In this work, we have been able to develop the Western ERG dune sand in the formulation of the molding which has been developed a mixture of sand, clay and adequate amount of water to avoid having mud in case of excess water and crumbling in the opposite case. After a series of tests on some examples of molds, we had a reproduction of the details of the model parts with detailed impressions and smooth and fine surfaces. The mixture does not disintegrate during the extraction of the model and will allow easy unplugging. Also, the mixture withstands the high temperature and erosion during the casting of the metal with sufficient permeability allowing the passage of gas produced. However, the physicochemical study tends to prove that this ERG sand has characteristics allowing it to be exploited in the industrial manufacturing and especially in the development of the molding. As a result, we can note that in industry, dune sand casting for series ranging from 1 to 100 , is more profitable for larger pieces from $40 \mathrm{~kg}$ to $2 \mathrm{~T}$, more time dune sand is very available in quantity and quality in our region. This type of sand has an economy compared to the beach sand currently used in molding. From the environmental point of view, the sand of the ERG is not similar in its natural properties to the sand of the beach, because it is very clean and it does not need to be washed, cleaned or rinsed so it has not any environmental impact on nature, because it is highly resistant to heat fusion during several molding operations is that it lose its physicochemical characteristics quickly.

\section{REFERENCES}

1. S. Bensaada, Machine molding (mechanical), 2009.

2. B. Michel, The sand casting, 2008.

3. B. Michel, Gravity metal shell casting, 2009.

4. P. Pascal, New Treaty of Mineral Chemistry, Volume 8F2, Metallurgy Review CNRS November 1994

5. S. Bensaada, The molding, Operation of manual execution of a sand mold, 2008.

6. J. Chavaillon, Stratigraphic study of the Quaternary formations of the Western North Sahara, Edition of the CNRS

7. M. Claude, Jean-Marc Linares industrialization of mechanical products Science3 Manufacturing Processes

8. M. Derruau, The forms of the terrestrial relief (Notions of geomorphologies), Edition MASSON, 1986

9. A. Tafraoui, Characterization and valorization of the sand of the western Algerian ERG in BUHP and tooling. University of Science and Technology HouariBoumediene 2007.

10. Solfaiman, Mohammad, and Mohammed Ali Nause Russel. "An Investigation to the Performance of the Voluntary Code of Corporate Governance in Bangladesh and the Scope for a Mandatory One."

11. A. Intes, h. Arnaudin, Characterization of sediments: dimensional criteria and indices, 1987

12. Engineering Techniques, Foundry and casting of aluminum alloys (M811, M812), foundry industry (M3500), molding and cored (M3512, M3513, M3514 and M3515), tools for shell foundry (M756) 
13. A. Chaoufi, A. Tafraoui, M. Zaoui, S. Tafraouid M. Dahmani. Research of the parameters of cut for the machiningof the new concretes. International Journal of Mechanical and Production, Engineering Research and Development (IJMPERD)ISSN (P): 2249-6890; ISSN (E): 2249-8001, Vol.7, Issue 6, Dec 2017, 321-332

14. Patel, P. J., and H. S. Patel. "Effect On Compressive And Flexural Strength Of High-Performance Concrete Incorporating Alccofine And Fly Ash." International Journal of Civil, Structural, Environmental and Infrastructure Engineering and Development 3.2 (2013): 109-114

15. Rajasekhar, E., and R. Jeevan Kumar. "Experimental investigation of gamma radiation shielding characteristics of wood." International Journal of Humanities 2 (2014): 21-26.

16. M. Zaoui, A. Tafraoui, A. Chaoufi, S. Tafraoui\& M. Dahmani. The realization of thin sheets stamping tools with an economical material. International Journal of Mechanical and Production, Engineering Research and Development (IJMPERD)ISSN (P): 2249-6890; ISSN (E): 2249-8001, Vol.7, Issue 6, Dec 2017, 437-444 
